\title{
Association of perioperative weight-based fluid balance with 30-day mortality and acute kidney injury among patients in the surgical intensive care unit
}

\author{
Tak Kyu Oh${ }^{1} \cdot$ In-Ae Song ${ }^{1} \cdot$ Sang-Hwan Do ${ }^{1} \cdot$ Sanghoon Jheon ${ }^{2} \cdot$ Cheong Lim $^{2}$
}

Received: 21 November 2018 / Accepted: 6 March 2019 / Published online: 27 March 2019

(c) Japanese Society of Anesthesiologists 2019

\begin{abstract}
Purpose Perioperative positive fluid balance has negative effects on short-term outcomes, such as surgical complications, although the associations with postoperative mortality remain unclear. This study evaluated the associations of perioperative fluid balance (FB) with 30-day mortality and acute kidney injury (AKI) after postoperative intensive care unit (ICU) admission.

Methods This retrospective study evaluated data from adult patients who were admitted to the ICU after surgery during 2012-2016. Weight-based cumulative FB (\%) was calculated for 3 time periods [postoperative day (POD) 0 (24 h), 0-1 $(48 \mathrm{~h})$, and $0-2(72 \mathrm{~h})]$ and was categorized as positive $(\geq 5 \%)$, mild to moderate positive $(5-10 \%)$, severe positive $(>10 \%)$, normal $(0-5 \%)$, or negative $(<0 \%)$.

Results Data from 7896 patients were included in the analysis. The multivariable Cox regression model revealed that increased 30-day mortality was associated with positive FB groups ( $\geq 5 \%)$ compared to normal FB groups (0-5\%) during 3 time periods [hazard ratio (HR) on POD 0 (24 h): 1.87, HR on POD 1 (48 h): 1.91, and HR on POD 2 (72 h): 4.62, all $P<0.05]$. These trends were more evident in the severe positive FB group across the three time periods. Additionally, similar association was found for incidence of AKI during POD 0-2.

Conclusion Perioperative cumulative weight-based FB was positively associated with increased postoperative 30-day mortality or postoperative AKI in ICU patients; this association was consistent with the positive FB on POD 0 (24 h), $0-1$ (48 h), and $0-2(72 \mathrm{~h})$.
\end{abstract}

Keywords Anesthesia $\cdot$ Critical care $\cdot$ Mortality

Tak Kyu Oh and In-Ae Song made equal contribution as co-first authors.

Electronic supplementary material The online version of this article (https://doi.org/10.1007/s00540-019-02630-8) contains supplementary material, which is available to authorized users.

Cheong Lim

mluemoon@snubh.org

1 Department of Anesthesiology and Pain Medicine, Seoul National University Bundang Hospital, Seongnam, South Korea

2 Department of Thoracic and Cardiovascular Surgery, Seoul National University Bundang Hospital, 166, Gumi-ro, Bundang-gu, 463-707 Seongnam, South Korea

\section{Introduction}

Perioperative fluid management can affect perioperative outcome [1], and several fluid management strategies have been studied in the clinical setting [2]. The most common strategies are liberal fluid therapy and restricted fluid therapy [3]. Restricted fluid therapy aims to achieve "zero fluid balance (FB)," and it has been associated with fewer postoperative complications and shorter hospital stays in some previous studies [3, 4]. However, recent trials have indicated that restricted fluid therapy may not prevent complications after surgery (e.g., laparoscopic colorectal surgery or pancreatectomy) [5-7]. In addition, four phases of fluid therapy, regarding early or late conservative fluid management, have been suggested [8]. However, there are controversies regarding the optimal timing of fluid resuscitation among early adequate goal-directed fluid management (e.g., 
$4 \mathrm{~mL} / \mathrm{kg} / 15 \mathrm{~min}-30 \mathrm{~mL} / \mathrm{kg} / 3 \mathrm{~h}$ ) [9], late conservative fluid management (defined as 2 consecutive negative FBs) [10], and late goal-directed fluid removal [11-13]. Thus, the optimal fluid management strategy remains controversial, and there are insufficient studies regarding the outcomes of these strategies.

Compared to patients admitted to a general ward, patients admitted to the intensive care unit (ICU) after surgery are in a critical condition [14]. Further, approximately $40 \%$ of patients admitted to the ICU after surgery are in a state of fluid overload [15], which might be associated with poor surgical and short-term outcomes [16, 17]. However, few studies have evaluated perioperative fluid management among only patients admitted to the ICU after surgery. Previous studies have analyzed cumulative FB based on input and output values, although recent studies have used calculations for fluid overload that were based on the patient's weight at admission [18, 19]. Those analyses calculated cumulative FB as a percentage of body weight and are useful for critically ill patients who require careful fluid management $[17$, $18,20]$.

The present study aimed to determine whether weightbased perioperative cumulative FB was associated with 30-day mortality or acute kidney injury (AKI) among patients who were admitted to the ICU after surgery.

\section{Methods}

This retrospective study was approved by the institutional review board (IRB) of the Seoul National University Bundang Hospital (SNUBH; B-1806/474-105). Because this was a retrospective review of patient medical records informed consent was waived by the IRB. The SNUBH is a 1360bed tertiary care hospital with 4 ICUs (medical, surgical, emergency, and neurologic ICUs) consisting of 102 beds. Approximately 150 surgeries are performed each day across 36 operating rooms. After surgery, patients are generally sent to the surgical, emergency, or neurologic ICUs, where 3 intensivists provide day-time postoperative care.

\section{Patients}

The medical records of all adult patients ( $>19$ years old) who were admitted to an ICU after elective or emergency surgery between January 1, 2012 and June 30, 2016 were evaluated for this study. The exclusion criteria were as follows: incomplete medical records, patients with preoperative heart failure (left ventricle ejection fraction of $<45 \%$ ), and patients who died on postoperative day (POD) 0-3 (first $72 \mathrm{~h}$ ), as the cumulative FB could not be calculated for those patients. If a patient underwent 2 or more surgeries and was admitted to the ICU 2 or more times, only most recent ICU admission was included in the analysis.

\section{Main independent variables: cumulative FB (\%) on POD 0 (24 h), 0-1 (48 h), and 0-2 (72 h)}

Cumulative FB was calculated as a percentage for all included patients across 3 time periods: POD $0(24 \mathrm{~h}$; include intraoperative FB), POD 0-1 (48 h), and POD 0-2 $(72 \mathrm{~h})$ Based on previous studies $[18,19]$, we calculated the cumulative $\mathrm{FB}(\%)$ as follows:

Cumulative FB (\%) = (fluid input - output in liters)

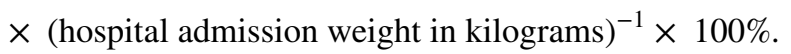

For example $10 \%$ positive in a patient whose body weight was $50 \mathrm{~kg}$ means $5000 \mathrm{~mL}$ positive FB. Fluid input was defined as all types of intravenous and enteral fluids that were used for maintenance or resuscitation (e.g., colloids, crystalloids, blood products, drug infusions, enteral nutrition, and parenteral nutrition). Fluid output was defined as all types of eliminated and removed fluids (e.g., drains, rectal, orogastric, nasogastric, and urine output). Weight measured on hospital admission $(\mathrm{kg})$ before surgery was measured using digital scales for patients who could stand by themselves and hospital beds with a weighing function for patients who could not stand.

All patients were subsequently categorized based on their cumulative FB; the categories were as follows: positive $\mathrm{FB}$ $(\geq 5 \%)$, normal FB $(0-5 \%)$, or negative $\mathrm{FB}(<0 \%)$. In addition, the positive FB group was divided into 2 groups, mild or moderate positive FB (5-10\%) and severe FB (>10\%), based on previous definitions [21]. During the study period, there was no specific protocol for fluid management in the ICU for ICU physicians.

\section{Potential covariates (measurements)}

This study collected data regarding the following variables: sex, age, body mass index $\left(\mathrm{kg} / \mathrm{m}^{2}\right)$, preoperative American Society of Anesthesiologists classification, Acute Physiology and Chronic Health Evaluation II score at ICU admission, preoperative comorbidities [hypertension, diabetes, ischemic heart disease (stable angina to myocardial infarction), cerebrovascular disease, and chronic kidney disease], type of surgery (cardiac/non-cardiac surgery), diagnosis of cancer, emergency surgery, estimated blood loss $(\mathrm{mL})$, operative time ( $\mathrm{min})$, the duration of ICU and hospital stay (days), and treatment in the ICU on POD 0-2 (total input of $0.9 \% \mathrm{NaCl}$, balanced crystalloid, and hydroxyethyl starch, renal replacement therapy, ventilator care, and vasopressors use). 


\section{Dependent variables (30-day mortality, acute kidney injury) and aim of the study}

The primary outcome of this study was defined as the association between 30-day mortality and cumulative FB on POD 0 (24 h), POD 0-1 (48 h), and POD 0-2 (72 h), following postoperative ICU admission. In addition, the effect of timing of cumulative FB [early: POD $0(24 \mathrm{~h})$ and late: POD 0-2 (72 h)] on the association with 30-day mortality was analyzed. Secondary outcome of this study was defined as the association between incidence of AKI during POD 0-2 (72 h) and cumulative FB on POD 0 (24 h), POD 0-1 (48 h), and POD 0-2 (72 h), following postoperative ICU admission. For diagnosis of AKI, this study followed the criteria of Kidney Disease: Improving Global Outcomes (creatinine only) (Online Resource 1) [22].

\section{Statistical analysis}

The demographic characteristics of the 3 groups (positive, normal, and negative FBs) were compared using the Chi square test for categorical variables and one-way analysis of variance for continuous variables. The simple relationship between cumulative FB during the 3 perioperative periods (POD 0, POD 0-1, and POD 0-2) was evaluated using restricted cubic splines. Then, univariable Cox regression analysis was performed for 30-day mortality and covariates with $P<0.1$ in the univariable Cox regression model were included in the final multivariable Cox regression analysis. Log-minus-log plots were used to investigate whether the central assumption of Cox proportional hazards model was satisfied, and the results were reported as hazard ratios (HRs) and 95\% confidence intervals (CIs). For secondary outcome (AKI), univariable logistic regression analysis was performed and covariates with $P<0.1$ in the univariable logistic regression model were included in the final multivariable logistic regression analysis. The results of the logistic regression model were reported as odds ratios (OR)s and $95 \%$ CIs. Differences with a $P$ value of $<0.05$ were considered statistically significant. All analyses were performed by statisticians from the Medical Research Collaborating Center in SNUBH using IBM SPSS software (version 23.0; IBM Corp., Armonk, NY, USA).

\section{Results}

During the study period, 9171 adult patients underwent 10,475 surgeries and were admitted to the ICU. A total of 1304 cases of postoperative ICU admissions were excluded due to repeated admissions from patients previously admitted to the ICU during the study period. In these instances, only the most recent admission for each patient was included in the analysis. Next, we excluded 168 patients who died on POD 0-3 (first 72 h), 1096 patients who had inaccurate or missing medical records, and 11 patients with preoperative heart failure (left ventricle ejection fraction of $<45 \%$ ). Thus, 7896 patients were included in the final analysis (Fig. 1). The patients were categorized into positive $(\geq 5 \%)$, normal $(0-5 \%)$, and negative $(<0 \%) \mathrm{FB}$ groups based on values calculated during POD 0 (24 h), 0-1 (48 h), and 0-2 (72 h) (Table 1). The demographic and clinical data of patients according to cumulative FB groups, as calculated on POD 0-2 (72 h), are shown in Table 2. A total of 330 patients died in the 30 days following ICU admission (4.2\%) and shown in Online Resource 2, and 30-day mortality according to the type of surgery performed is presented in Online Resource 3.

\section{Thirty-day mortality after postoperative ICU admission}

The relationship between 30-day mortality after surgical ICU admission and cumulative FB on POD 0 (24 h) (A), 0-1 (48 h) (B), and 0-2 (48 h) (C) is shown in Fig. 2. The $\log$ odds of 30-day mortality according to cumulative FB during the 3 time periods increased with an increase in the cumulative FB.

Online Resource 4 shows the results of the univariable Cox regression analysis for 30-day mortality. Table 3 shows the results of the multivariable Cox regression analysis for 30-day mortality, adjusted for covariates with $P<0.1$ in the univariable Cox regression model. Compared to normal FB groups, positive associations with 30-day mortality were seen for mild or moderate positive FB groups (5-10\%) on

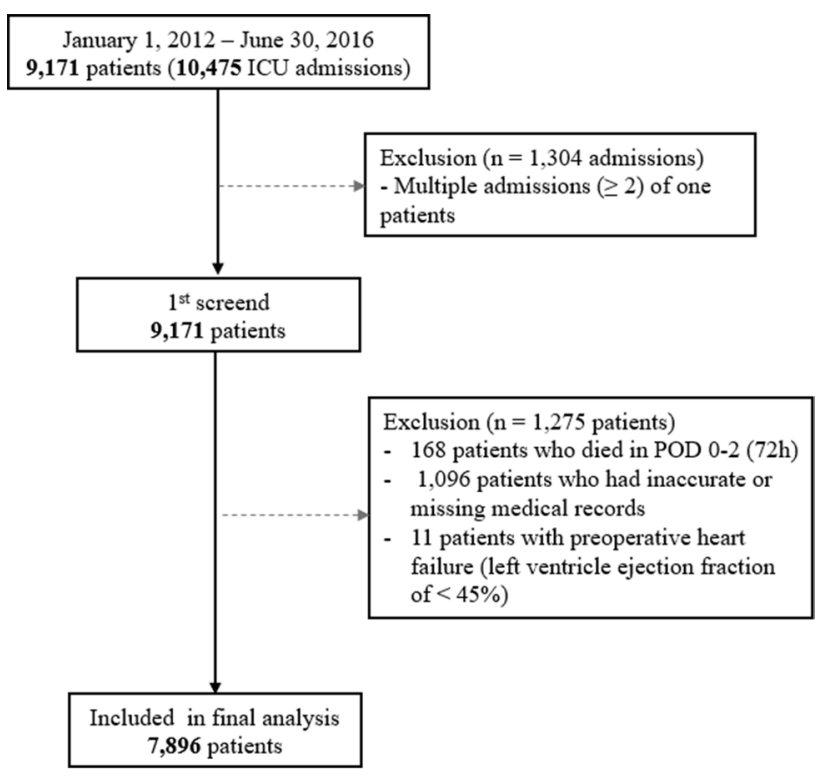

Fig. 1 Flow chart for patient selection. ICU, intensive care unit; POD, postoperative day 
Table 1 Classification of three groups (positive $\geq 5 \%$, $0 \leq$ normal $<5 \%$, negative $<0 \%$ ) by three criterias [POD $0(24 \mathrm{~h})$, POD 0-1 (48 h), POD 0-2 (72 h)]

\begin{tabular}{llrl}
\hline Variables & Fluid balance (total patients, $n=7896)$ & Median & Interquartile range \\
\hline Fluid balance in POD 0 (24 h) & Positive $(n=837)$ : input-output, $\mathrm{mL}$ & 3973.3 & 3311.2 to 5097.2 \\
& Fluid balance, $\%$ & 6.8 & 5.7 to 8.7 \\
& Normal $(n=5536)$ : input-output, $\mathrm{mL}$ & 979.8 & 502.2 to 1627.1 \\
& Fluid balance, $\%$ & 1.6 & 0.8 to 2.7 \\
& Negative $(n=1523)$ : input-output, $\mathrm{mL}$ & -510.0 & -990.2 to -216.7 \\
& Fluid balance, $\%$ & -0.8 & -1.6 to -0.3 \\
Fluid balance in POD 0-1 (48 h) & Positive $(n=858)$ : input-output, $\mathrm{mL}$ & 3910.6 & 3272.8 to 5049.3 \\
& Fluid balance, $\%$ & 6.7 & 5.7 to 8.7 \\
& Normal $(n=5422)$ : input-output, $\mathrm{mL}$ & 999.5 & 535.0 to 1652.0 \\
& Fluid balance, $\%$ & 1.7 & 0.8 to 2.7 \\
& Negative $(n=1616)$ : input-output, $\mathrm{mL}$ & -528.7 & -1.6 to -0.4 \\
& Fluid balance, $\%$ & -0.9 & -1.6 to -0.4 \\
Fluid balance in POD 0-2 (72 h) & Positive $(n=229)$ : input-output, $\mathrm{mL}$ & 3492.1 & 2915.7 to 4462.4 \\
& Fluid balance, $\%$ & 6.2 & 5.5 to 7.9 \\
& Normal $(n=6077)$ : input-output, $\mathrm{mL}$ & 1029.7 & 553.4 to 1567.5 \\
& Fluid balance, $\%$ & 1.7 & 0.9 to 2.6 \\
& Negative $(n=1590)$ : input-output, $\mathrm{mL}$ & -509.5 & -998.3 to -214.3 \\
& Fluid balance, $\%$ & -0.8 & -1.6 to -0.4 \\
\hline
\end{tabular}

Group of cumulative fluid balance: positive $\geq 5 \%, 0 \leq$ normal $<5 \%$, NEGATIVE $<0 \%$

$P O D$ postoperative day, $I C U$ intensive care unit, $A d m$ admission
POD 0 (24 h) (HR 1.87, 95\% CI 1.22-2.86, $P=0.004)$, POD $0-1$ (48 h) (HR 1.91, 95\% CI 1.25-2.91, $P=0.003)$, and on POD 0-2 (72 h) (HR 4.62, 95\% CI 2.75-7.76, $P<0.001)$. Compared to normal FB groups, positive associations with 30-day mortality were also seen for severe positive FB groups $(>10 \%)$ on POD $0(24 \mathrm{~h})(\mathrm{HR} 2.98,95 \% \mathrm{CI}$ 1.59-5.57, $P=0.001)$, POD 0-1 (48 h) (HR 3.17, 95\% CI 1.70-5.92, $P<0.001$ ), and on POD 0-2 (72 h) (HR 8.83, 95\% CI 4.03-19.33, $P<0.001)$. However, negative FB groups showed no significant association with 30-day mortality across the 3 time periods $(P>0.05)$. Similar trend was observed in patients who admitted ICU after non-cardiac surgery (Online Resource 5). Compared to those in the normal FB groups, patients in the severe positive FB groups (>10\%) (HR 4.43, 95\% CI 1.65-11.89, $P=0.003$ ) and mild or moderate positive FB groups (5-10\%) (HR 15.86, 95\% CI 4.65-55.18, $P<0.001)$ on POD 0-2 (72 h) admitted to the ICU after cardiac surgery (Online Resource 6), had a higher 30-day mortality rate, although this difference was not significant $(P>0.05)$ on POD $0(24 \mathrm{~h})$ and POD 0-3 (48 h).

\section{Early and late cumulative FB and 30-day mortality after postoperative ICU admission}

Table 4 shows the results of multivariable Cox regression analysis considering the timing of cumulative FB. Compared to the negative or normal FB on POD $0(24 \mathrm{~h})$ and on POD 0-2 (72 h) group, the negative or normal FB on POD $0(24 \mathrm{~h})+$ positive FB on POD 0-2 (72 h) group was associated with a 4.52 times increase in 30-day mortality (HR 4.52, 95\% CI 2.60-7.85, $P<0.001$ ). The positive FB on POD $0(24 \mathrm{~h})+$ negative or normal FB on POD 0-2 $(72 \mathrm{~h})$ group and the positive FB on POD $0(24 \mathrm{~h})+$ positive FB on POD 0-2 (72 h) group were associated with a 2.21 times (HR 2.21, 95\% CI 1.45-3.38, P<0.001) and 12.12 times (HR 12.12, 95\% CI 6.11-24.03, $P<0.001$ ) increase in 30-day mortality, compared to the negative or normal FB on POD 0 (24 h) and on POD 0-2 (72 h) group.

\section{Acute kidney injury after postoperative ICU admission}

Online Resource 7 and Table 5 show the results of univariable and multivariable logistic regression analyses for AKI during POD 0-2 according to FB. Compared to normal FB groups, positive associations with AKI were seen for mild or moderate positive FB groups (5-10\%) on POD 0 (24 h) (OR 1.74, 95\% CI 1.39-2.19, $P<0.001)$, POD 0-1 (48 h) (OR 1.68, 95\% CI 1.34-2.10, $P<0.001$ ), and on POD 0-2 (72 h) (OR 1.66, 95\% CI 1.15-2.39, $P=0.007)$. Compared to normal FB groups, positive associations with AKI were also seen for severe positive FB groups ( $>10 \%)$ on POD 0 (24 h) (OR 1.84, 95\% CI 1.25-2.51, $P=0.025)$, POD 0-1 (48 h) (OR 1.98, 95\% CI 1.53-2.50, $P<0.001$ ), and on POD 0-2 (72 h) (OR 1.97, 95\% CI 1.15-5.05, $P=0.035)$. However, negative FB groups showed no significant association with AKI across the 3 time periods $(P>0.05)$. 
Table 2 Patient's characteristics, surgical variables and outcomes according to three groups of perioperative cumulative fluid balance (\%) after postoperative ICU admission

\begin{tabular}{|c|c|c|c|c|}
\hline \multirow[t]{3}{*}{ Variable } & \multicolumn{3}{|c|}{ Fluid balance (\%) in Postoperative day 0-2 (72 h) } & \multirow[t]{3}{*}{$P$ value } \\
\hline & Positive & Normal & Negative & \\
\hline & $N=229$ & $N=6077$ & $N=1590$ & \\
\hline Age, year & $64.8(14.9)$ & $61.1(15.5)$ & $58.3(15.5)$ & $<0.001$ \\
\hline Sex, Male & $122(53.3 \%)$ & $3498(57.6 \%)$ & $903(56.8 \%)$ & 0.396 \\
\hline Body mass index, $\mathrm{kg} / \mathrm{m}^{2}$ & $22.5(3.7)$ & $24.0(3.7)$ & $23.9(3.7)$ & $<0.001$ \\
\hline APACHE II & $23.8(9.0)$ & $20.4(7.8)$ & $20.3(8.0)$ & $<0.001$ \\
\hline ASA class & & & & $<0.001$ \\
\hline 1 & $38(16.6 \%)$ & $1243(20.5 \%)$ & $389(24.5 \%)$ & \\
\hline 2 & $89(38.9 \%)$ & $2596(42.7 \%)$ & $674(42.4 \%)$ & \\
\hline$\geq 3$ & $102(44.5 \%)$ & $2238(36.8 \%)$ & $527(33.1 \%)$ & \\
\hline \multicolumn{5}{|l|}{ Preoperative comorbidity } \\
\hline Hypertension & $63(27.5 \%)$ & $1595(26.2 \%)$ & $370(23.3 \%)$ & 0.044 \\
\hline Diabetes mellitus & $31(13.5 \%)$ & $854(14.1 \%)$ & $188(11.8 \%)$ & 0.069 \\
\hline Ischemic heart disease & $43(18.8 \%)$ & $1120(18.4 \%)$ & $184(11.6 \%)$ & $<0.001$ \\
\hline Neurologic disease & $11(4.8 \%)$ & $673(11.1 \%)$ & $202(12.7 \%)$ & 0.001 \\
\hline Chronic kidney disease & $24(10.5 \%)$ & $386(6.4 \%)$ & $82(5.2 \%)$ & 0.006 \\
\hline Cancer & $79(34.5 \%)$ & $3791(33.5 \%)$ & $1049(34.0 \%)$ & 0.903 \\
\hline Advanced cancer & $7(3.1 \%)$ & $310(5.1 \%)$ & $70(4.4 \%)$ & 0.219 \\
\hline Types of surgical procedures & & & & $<0.001$ \\
\hline Cardiac surgery & $83(36.2 \%)$ & $1614(26.6 \%)$ & $254(16.0 \%)$ & \\
\hline Non-cardiac surgery & $146(63.8 \%)$ & $4463(73.4 \%)$ & $1336(84.0 \%)$ & \\
\hline Surgery time, $\min$ & $292.6(154.0)$ & $223.9(121.2)$ & $230.1(137.2)$ & $<0.001$ \\
\hline Emergency surgery & $84(36.7 \%)$ & $1235(20.3 \%)$ & $389(24.5 \%)$ & $<0.001$ \\
\hline Length of ICU stay, day & $3.5(11.2)$ & $2.2(6.8)$ & $3.3(8.8)$ & $<0.001$ \\
\hline Length of hospital stay, day & $31.3(35.7)$ & $24.0(39.2)$ & $30.2(62.5)$ & $<0.001$ \\
\hline Renal replacement therapy in POD $0-2$ & $38(16.6 \%)$ & $105(1.7 \%)$ & $67(4.2 \%)$ & $<0.001$ \\
\hline Ventilator use in POD $0-2$ & $129(56.3 \%)$ & $3513(57.8 \%)$ & $860(54.1 \%)$ & 0.028 \\
\hline Estimated blood loss, mL & $1490.6(2788.9)$ & $605.7(1037.5)$ & 786.5 (1369.7) & $<0.001$ \\
\hline Vasopressor use in POD 0-2 & $202(88.2 \%)$ & $4665(16.8 \%)$ & $1302(81.9 \%)$ & 0.001 \\
\hline \multicolumn{5}{|l|}{ Total input fluid $(\mathrm{mL} / \mathrm{kg})$ in POD $0-2$} \\
\hline $0.9 \% \mathrm{NaCl}$ & $111.5(84.5)$ & $82.6(61.9)$ & $98.7(69.7)$ & $<0.001$ \\
\hline Balanced crystalloid & $58.6(42.0)$ & $40.2(32.7)$ & $31.9(32.9)$ & $<0.001$ \\
\hline Hydroxyethyl starch & $23.5(26.6)$ & $12.7(15.5)$ & $14.2(17.5)$ & $<0.001$ \\
\hline 30-day mortality & $55(24.0 \%)$ & $209(3.4 \%)$ & $66(4.2 \%)$ & $<0.001$ \\
\hline $\mathrm{AKI}$ in POD $0-2$ & $87(38.0 \%)$ & $1082(19.0 \%)$ & $281(19.4 \%)$ & $<0.001$ \\
\hline
\end{tabular}

Group of fluid balance: positive $\geq 5 \%, 0 \leq$ normal $<5 \%$, negative $<0 \%$. The data were represented as mean (standard deviation) or number (percentage)

$I C U$ intensive care unit, $A P A C H E$ acute physiology and chronic health evaluation, ASA American Society of Anesthesiologists, $P O D$ postoperative day, $A K I$ acute kidney injury

\section{Discussion}

The present study revealed that patients with positive $\mathrm{FB}$ on POD 0 (24 h), POD 0-1 (48 h), and POD 0-2 (72 h) were associated with an increase in 30-day mortality relative to patients in the normal FB group. A similar association was found for incidence of AKI during POD 0-2. Furthermore, the group that had normal or negative FB in the early period (POD 0) with normal or negative FB in the late period was associated with better 30-day mortality compared to the other groups. The present study is novel because we used weight-based perioperative cumulative FB to investigate the association with 30-day mortality or AKI among patients who were admitted to the ICU after surgery. Furthermore, we evaluated the effect of early or late cumulative FB status on the mortality of ICU patients. Considering the different fluid management strategies recommended nowadays for shock patients in the early and late periods [8], our results could provide useful information in clinical practice for surgical ICU patients. 

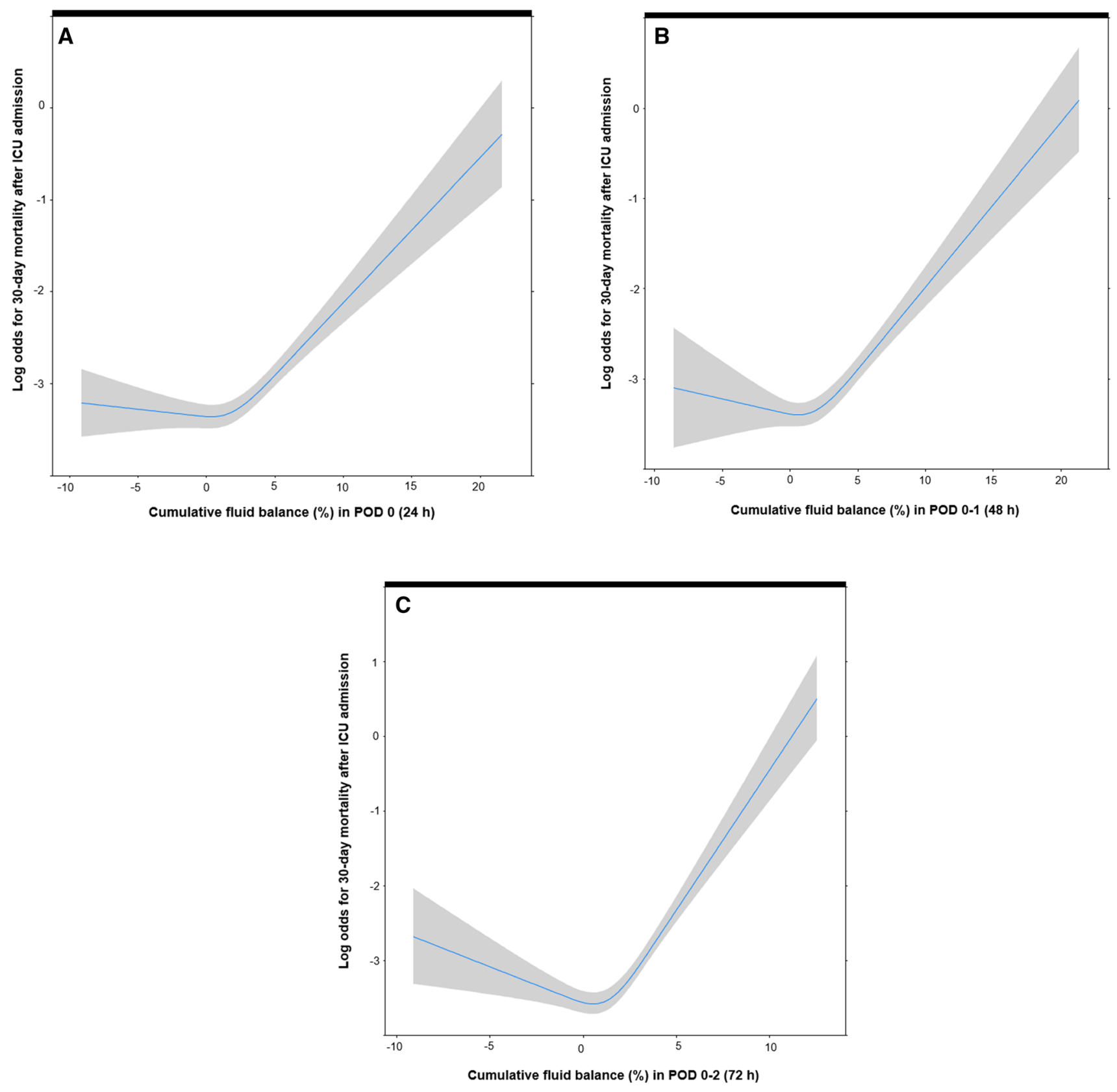

Fig. 2 Restricted cubic splines for 30-day mortality according to cumulative fluid balance (\%) in POD 0, 24 h (a), fluid balance in POD 0-1, $48 \mathrm{~h}$ (b) and fluid balance in POD $0-2,72 \mathrm{~h}$ (c) after the postoperative admission to the ICU. ICU intensive care unit, $P O D$ postoperative day

An interesting finding of this study was that the proportion of patients in the positive FB group decreased to $2.9 \%(229 / 7896)$ on POD 0-2 (72 h) compared to $10.6 \%$ (837/7896) on POD 0 (24 h). This may mean that there was an inevitable positive FB on POD 0 , especially during the intraoperative period, to replace ongoing bleeding. Patients in the positive FB group on POD 0-2 (72 h) might be the most severe group included in this study, as they failed to recover to normal FB due to many factors (e.g., shock, sepsis, or bleeding). This is reflected by the relatively higher APACHE II score of the positive FB during POD 0-2 (mean 23.8). In addition, although there is a possible risk with the use of hydroxyethyl starch in ICU patients [23], physicians at SNUBH sometimes used hydroxyethyl starch to replace ongoing or massive bleeding with transfusion. As a result, patients with positive $\mathrm{FB}$ in the early period (POD 0) were treated to return to normal fluid status in our institution, and despite these efforts, the positive FB group in the late period (POD 0-3) had high mortality in this study. 
Table 3 Multivariable Cox regression analysis for 30-day after postoperative ICU admission according to perioperative cumulative fluid balance $(\%)$

\begin{tabular}{|c|c|c|}
\hline \multirow[t]{2}{*}{ Variables } & \multicolumn{2}{|l|}{ 30-day readmission } \\
\hline & Hazard ratio $(95 \% \mathrm{CI})$ & $P$ value* \\
\hline \multicolumn{3}{|l|}{ Cumulative FB in postoperative day 0 ( $24 \mathrm{~h})$} \\
\hline Normal $(0-5 \%), n=5538$ & 1 & $(<0.001)$ \\
\hline Negative $(<0 \%), n=1523$ & $0.72(0.43-1.19)$ & 0.197 \\
\hline Positive: mild, moderate $(5-10 \%), n=700$ & $1.87(1.22-2.86)$ & 0.004 \\
\hline Positive: severe ( $>10 \%), n=135$ & $2.98(1.59-5.57)$ & 0.001 \\
\hline \multicolumn{3}{|l|}{ Cumulative FB in postoperative day $0-1$ (48 h) } \\
\hline Normal $(0-5 \%), n=5423$ & 1 & $(<0.001)$ \\
\hline Negative $(<0 \%), n=1616$ & $0.69(0.41-1.16)$ & 0.162 \\
\hline Positive: mild, moderate (5-10\%), $n=715$ & $1.91(1.25-2.91)$ & 0.003 \\
\hline Positive: severe ( $>10 \%), n=142$ & $3.17(1.70-5.92)$ & $<0.001$ \\
\hline \multicolumn{3}{|l|}{ Cumulative FB in postoperative day $0-2(72 \mathrm{~h})$} \\
\hline Normal $(0-5 \%), n=6077$ & 1 & $(<0.001)$ \\
\hline Negative $(<0 \%), n=1590$ & $1.37(0.91-2.07)$ & 0.136 \\
\hline Positive: mild, moderate (5-10\%), $n=202$ & $4.62(2.75-7.76)$ & $<0.001$ \\
\hline Positive: severe ( $>10 \%), n=27$ & $8.83(4.03-19.33)$ & $<0.001$ \\
\hline \multicolumn{3}{|c|}{$\begin{array}{l}I C U \text { intensive care unit, } C I \text { confidence interval, } F B \text { fluid balance, } P O D \text { postoperative day, } A P A C H E \text { acute } \\
\text { physiology and chronic health evaluation, } A S A \text { American Society of Anesthesiologists }\end{array}$} \\
\hline \multicolumn{3}{|c|}{$\begin{array}{l}* \text { Covariates of } P<0.1 \text { in univariable cox regression analysis in Online Resource } 4 \text { were included in each } \\
\text { multivariable cox regression analysis (age, body mass index, APACHE II, ASA physical status, emergency } \\
\text { surgery, surgery time, hypertension, ischemic heart disease, cerebrovascular disease, advanced cancer, ven- } \\
\text { tilator use in POD } 0-2 \text {, vasopressor use, } 0.9 \% \mathrm{NaCl} \text { infused in POD } 0-2 \text {, Balanced crystalloid infused in } \\
\text { POD 0-2, and hydroxyethyl starch infused in POD 0-2) }\end{array}$} \\
\hline
\end{tabular}

Table 4 Multivariable cox regression analysis for 30-day after postoperative ICU admission according to early (POD 0) and late (POD 0-2) perioperative cumulative fluid balance $(\%)$

\begin{tabular}{llc}
\hline Variables & 30 -day mortality \\
\cline { 2 - 3 } & Hazard ratio (95\% CI) & $P$ value* \\
\hline Negative or normal FB in POD 0 $(24 \mathrm{~h})+$ negative or normal FB in 0-2 $(72 \mathrm{~h}), n=6887(87.2 \%)$ & 1 & $(<0.001)$ \\
Negative or normal FB in POD 0 $(24 \mathrm{~h})+$ positive FB in POD 0-2 $(72 \mathrm{~h}), n=172(2.2 \%)$ & $4.52(2.60-7.85)$ & $2.21(1.45-3.38)$ \\
Positive FB in POD 0 (24 h) + negative or normal FB in POD 0-2 $(72 \mathrm{~h}), n=780(9.9 \%)$ & $12.12(6.11-24.03)$ & $<0.001$ \\
Positive FB in POD 0 $(24 \mathrm{~h})+$ positive FB in POD 0-2 $(72 \mathrm{~h}), n=57(0.7 \%)$ & $<0.001$ \\
\hline
\end{tabular}

Group of fluid balance: positive $\geq 5 \%, 0 \leq$ normal $<5 \%$, negative $<0 \%$

$I C U$ intensive care unit, $P O D$ postoperative day, $C I$ confidence interval, $F B$ fluid balance, $A P A C H E$ acute physiology and chronic health evaluation, ASA American Society of Anesthesiologists

*Covariates of $P<0.1$ in univariable cox regression analysis in Online Resource 4 were included in each multivariable cox regression analysis (age, body mass index, APACHE II, ASA physical status, emergency surgery, surgery time, hypertension, ischemic heart disease, cerebrovascular disease, advanced cancer, ventilator use in POD 0-2, vasopressor use, $0.9 \% \mathrm{NaCl}$ infused in POD 0-2, Balanced crystalloid infused in POD 0-2, and Hydroxyethyl starch infused in POD 0-2)

The results of this study are consistent with the findings of recent studies [16, 24], which have indicated that fluid overload is associated with survival after colorectal surgery and esophagectomy. However, those studies [16, 24] examined patients who were healthier than the patients in our present study, as approximately $30-40 \%$ of patients in our study had an American Society of Anesthesiologists classification of $\geq 3$. In addition, fluid accumulation is a potential risk factor for mortality [25], and Shen et al. [26] recently reported that positive FB was associated with a higher incidence of postoperative acute kidney injury (AKI), while negative FB was not associated with a lower incidence of postoperative AKI. These results suggest that it is important to maintain a normal FB during the perioperative period.

Although previous studies have evaluated perioperative fluid overload using only fluid input $[5,6,16]$, the present study used an input/output calculation based on the patient's weight at the time of admission. This approach was also used by Golstein et al. in 2001 [27] and has generally been used when FB needs to be precisely calculated (e.g., in the ICU or 
Table 5 Multivariable logistic regression analysis for occurrence of AKI during POD $0-2$ according to perioperative cumulative fluid balance (\%)

\begin{tabular}{|c|c|c|}
\hline \multirow[t]{2}{*}{ Variables } & \multicolumn{2}{|l|}{ Acute kidney injury } \\
\hline & Odds ratio $(95 \% \mathrm{CI})$ & $P$ value* \\
\hline \multicolumn{3}{|l|}{ Cumulative FB in postoperative day $0(24 \mathrm{~h})$} \\
\hline Normal $(0-5 \%), n=5538$ & 1 & $(<0.001)$ \\
\hline Negative $(<0 \%), n=15,231.00(0.84,1.19)$ & $1.00(0.84,1.19)$ & 0.973 \\
\hline Positive: mild, moderate $(5-10 \%), n=700$ & $1.74(1.39,2.19)$ & $<0.001$ \\
\hline Positive: severe ( $>10 \%), n=135$ & $1.84(1.25,2.51)$ & 0.025 \\
\hline \multicolumn{3}{|l|}{ Cumulative FB in postoperative day $0-1$ ( $48 \mathrm{~h})$} \\
\hline Normal $(0-5 \%), n=5423$ & 1 & $(<0.001)$ \\
\hline Negative $(<0 \%), n=1616$ & $1.00(0.84,1.19)$ & 1.00 \\
\hline Positive: mild, moderate (5-10\%), $n=715$ & $1.68(1.34,2.10)$ & $<0.001$ \\
\hline Positive: severe ( $>10 \%), n=142$ & $1.98(1.53,2.50)$ & $<0.001$ \\
\hline \multicolumn{3}{|l|}{ Cumulative FB in postoperative day $0-2(72 \mathrm{~h}$ ) } \\
\hline Normal $(0-5 \%), n=6077$ & 1 & $(0.021)$ \\
\hline Negative $(<0 \%), n=1590$ & $0.95(0.79,1.13)$ & 0.549 \\
\hline Positive: mild, moderate (5-10\%), $n=202$ & $1.66(1.15,2.39)$ & 0.007 \\
\hline Positive: severe ( $>10 \%), n=27$ & $1.97(1.15,5.05)$ & 0.035 \\
\hline \multicolumn{3}{|c|}{$\begin{array}{l}I C U \text { intensive care unit, } F B \text { fluid balance, } P O D \text { postoperative day, } A P A C H E \text { acute physiology and chronic } \\
\text { health evaluation, } A S A \text { American Society of Anesthesiologists }\end{array}$} \\
\hline \multicolumn{3}{|c|}{$\begin{array}{l}\text { *Covariates of } P<0.1 \text { in univariable logistic regression analysis in Online Resource } 7 \text { were included in } \\
\text { each multivariable logistic regression analysis (sex, age, body mass index, APACHE, ASA physical sta- } \\
\text { tus; emergency surgery; surgery time, diabetes mellitus, ischemic heart disease, cerebrovascular disease, } \\
\text { chronic kidney disease, cardiac surgery, ventilator use in POD } 0-2 \text {, intraoperative estimated blood loss, } \\
\text { vasopressor use in POD } 0-2,0.9 \% \mathrm{NaCl} \text { infused in POD } 0-2 \text {, Balanced crystalloid infused in POD } 0-2 \text {, } \\
\text { and hydroxyethyl starch infused in POD 0-2) }\end{array}$} \\
\hline
\end{tabular}

pediatric settings) $[17,18,20]$. Considering that the estimation of weight is important for ICU patients [28], analyzing FB using weight on admission could be beneficial in predicting positive associations for postoperative mortality in ICU patients. In addition, this association should be considered carefully, as there might be many cases of inevitable positive FB due to excessive bleeding, comorbidities, or cardiovascular instability in the perioperative period. Therefore, restrictive fluid therapy to avoid excessive positive FB should be considered in conjunction with good surgical skills and quick and definitive control of bleeding for improved 30-day mortality after surgery in ICU patients.

A recent clinical trial, known as the RELIEF trial, showed that there was no significant difference in mortality between restrictive and liberal fluid therapy groups for patients, following major abdominal surgery [29]. The RELIEF trial showed that a liberal fluid therapy strategy in the perioperative period did not increase mortality more than restrictive fluid therapy, which appears to be different from the results in our observational study. However, careful consideration is required to compare the results of our study with the RELIEF trial [29]. First, the RELIEF trial focused on patients who underwent major abdominal surgery, which usually requires a large volume of fluid infusion to maintain organ perfusion. In addition, the RELIEF trial excluded liver resection, end-stage renal disease patients, and cases of urgent or emergency surgery. Therefore, the effect of positive FB might be different from our study that focused on only postoperative surgical ICU patients.

The present study has several limitations. First, the retrospective design is associated with a known risk of bias. Furthermore, owing to the retrospective nature of this study, it is not possible to conclude about the causality between positive FB and mortality or whether the result is due to a compromised clinical course. Second, the use of patient data from a single center may limit the generalizability of the findings. For example, the SNUBH has intensivists that provide daytime postoperative ICU care, and further studies are needed to examine centers without certified intensivists and centers with all-day intensivists. Third, the heterogeneity of postoperative ICU admissions may affect the findings, due to the numerous surgery types. For example, patients who underwent cardiac surgery using a cardiopulmonary bypass pump are unable to avoid exposure to positive FB. Fourth, we did not consider fluid evaporation in the FB calculation, given the heterogeneity of the surgical procedures. In addition, although there were efforts to record information regarding fluid input and output, the accuracy of the information may not be perfect, due to various factors such as irrigation fluids or use of gauze swab during surgery. Fifth, we excluded patients who died on POD 0-2, although they were likely the most critically ill and their exclusion might have affected 
our findings. Sixth, we only included the patients' last surgical ICU admission during the study period, to satisfy the assumption that all individuals should be independent to be included in the Cox proportional hazard model. Considering that the fluid managements of patients might be different according to whether it was a first or repeat surgery, this is an important bias in our study. Last, we did not perform a subgroup analysis for patients with sepsis due to difficulty in diagnosing sepsis during the postoperative period. As fluid management for patients with sepsis is different from other patients [30], this factor might be a bias in this study.

In conclusion, this study showed that perioperative cumulative weight-based FB is positively associated with an increase in postoperative 30-day mortality or postoperative AKI in ICU patients, and this association was consistent with positive FB on POD 0 (24 h), 0-1 (48 h), and 0-2 $(72 \mathrm{~h})$.

Acknowledgements The authors thank the Medical Research Collaborating Center at Seoul National University Bundang Hospital for the revisions with regard to statistical analyses. They are particularly grateful to their statistician, Eunjeong Ji, Ph.D., for her contribution on the statistical analysis.

\section{References}

1. Jacob M, Chappell D, Rehm M. Clinical update: perioperative fluid management. Lancet. 2007;369(9578):1984-6.

2. Voldby AW, Brandstrup B. Fluid therapy in the perioperative setting — a clinical review. J Intensive Care. 2016;4:27.

3. Corcoran T, Rhodes JE, Clarke S, Myles PS, Ho KM. Perioperative fluid management strategies in major surgery: a stratified meta-analysis. Anesth Analg. 2012;114(3):640-51.

4. Futier E, Constantin JM, Petit A, Chanques G, Kwiatkowski F, Flamein R, Slim K, Sapin V, Jaber S, Bazin JE. Conservative vs restrictive individualized goal-directed fluid replacement strategy in major abdominal surgery: a prospective randomized trial. Arch Surg. 2010;145(12):1193-200.

5. Gomez-Izquierdo JC, Trainito A, Mirzakandov D, Stein BL, Liberman S, Charlebois P, Pecorelli N, Feldman LS, Carli F, Baldini G. Goal-directed fluid therapy does not reduce primary postoperative ileus after elective laparoscopic colorectal surgery: a randomized controlled trial. Anesthesiology. 2017;127(1):36-49.

6. Grant F, Brennan MF, Allen PJ, DeMatteo RP, Kingham TP, D'Angelica M, Fischer ME, Gonen M, Zhang H, Jarnagin W. Prospective randomized controlled trial of liberal vs restricted perioperative fluid management in patients undergoing pancreatectomy. Ann Surg. 2016;264(4):591-8.

7. Huang Y, Chua TC, Gill AJ, Samra JS. Impact of perioperative fluid administration on early outcomes after pancreatoduodenectomy: a meta-analysis. Pancreatology. 2017;17(3):334-41.

8. Malbrain M, Van Regenmortel N, Saugel B, De Tavernier B, Van Gaal PJ, Joannes-Boyau O, Teboul JL, Rice TW, Mythen M, Monnet X. Principles of fluid management and stewardship in septic shock: it is time to consider the four D's and the four phases of fluid therapy. Ann Intensive Care. 2018;8(1):66.

9. Marik PE, Malbrain M. The SEP-1 quality mandate may be harmful: How to drown a patient with $30 \mathrm{~mL} / \mathrm{kg}$ fluid! Anaesthesiol Intensive Ther. 2017;49(5):323-8.
10. Malbrain ML, Marik PE, Witters I, Cordemans C, Kirkpatrick AW, Roberts DJ, Van Regenmortel N. Fluid overload, deresuscitation, and outcomes in critically ill or injured patients: a systematic review with suggestions for clinical practice. Anaesthesiol Intensive Ther. 2014;46(5):361-80.

11. Cordemans C, De Laet I, Van Regenmortel N, Schoonheydt K, Dits H, Huber W, Malbrain ML. Fluid management in critically ill patients: the role of extravascular lung water, abdominal hypertension, capillary leak, and fluid balance. Ann Intensive Care 2012;2(Suppl 1):S1.

12. Murphy CV, Schramm GE, Doherty JA, Reichley RM, Gajic O, Afessa B, Micek ST, Kollef MH. The importance of fluid management in acute lung injury secondary to septic shock. Chest. 2009;136(1):102-9.

13. Rivers EP. Fluid-management strategies in acute lung injury-liberal, conservative, or both? $\mathrm{N}$ Engl J Med. 2006;354(24):2598-600.

14. Ghorra S, Reinert SE, Cioffi W, Buczko G, Simms HH. Analysis of the effect of conversion from open to closed surgical intensive care unit. Ann Surg. 1999;229(2):163-71.

15. Lowell JA, Schifferdecker C, Driscoll DF, Benotti PN, Bistrian BR. Postoperative fluid overload: not a benign problem. Crit Care Med. 1990;18(7):728-33.

16. Glatz T, Kulemann B, Marjanovic G, Bregenzer S, Makowiec F, Hoeppner J. Postoperative fluid overload is a risk factor for adverse surgical outcome in patients undergoing esophagectomy for esophageal cancer: a retrospective study in 335 patients. BMC Surg. 2017;17(1):6.

17. Xu J, Shen B, Fang Y, Liu Z, Zou J, Liu L, Wang C, Ding X, Teng J. Postoperative fluid overload is a useful predictor of the short-term outcome of renal replacement therapy for acute kidney injury after cardiac surgery. Medicine (Baltimore). 2015;94(33):e1360.

18. Balakumar V, Murugan R, Sileanu FE, Palevsky P, Clermont G, Kellum JA. Both positive and negative fluid balance may be associated with reduced long-term survival in the critically ill. Crit Care Med. 2017;45(8):e749-e57.

19. Selewski DT, Cornell TT, Lombel RM, Blatt NB, Han YY, Mottes T, Kommareddi M, Kershaw DB, Shanley TP, Heung M. Weightbased determination of fluid overload status and mortality in pediatric intensive care unit patients requiring continuous renal replacement therapy. Intensive Care Med. 2011;37(7):1166-73.

20. Chen J, Li X, Bai Z, Fang F, Hua J, Li Y, Pan J, Wang J, Feng $\mathrm{X}, \mathrm{Li}$ Y. Association of fluid accumulation with clinical outcomes in critically ill children with severe sepsis. PLoS One. 2016;11(7):e0160093.

21. O'Connor ME, Prowle JR. Fluid overload. Crit Care Clin. 2015;31(4):803-21.

22. Kellum JA, Lameire N, Group KAGW. Diagnosis, evaluation, and management of acute kidney injury: a KDIGO summary (part 1). Crit Care. 2013;17(1):204.

23. Myburgh JA, Finfer S, Bellomo R, Billot L, Cass A, Gattas D, Glass P, Lipman J, Liu B, McArthur C, McGuinness S. Hydroxyethyl starch or saline for fluid resuscitation in intensive care. $\mathrm{N}$ Engl J Med. 2012;367(20):1901-11.

24. Asklid D, Segelman J, Gedda C, Hjern F, Pekkari K, Gustafsson UO. The impact of perioperative fluid therapy on short-term outcomes and 5-year survival among patients undergoing colorectal cancer surgery - a prospective cohort study within an ERAS protocol. Eur J Surg Oncol. 2017;43(8):1433-9.

25. Bouchard J, Mehta RL. Fluid balance issues in the critically ill patient. Contrib Nephrol. 2010;164:69-78.

26. Shen Y, Zhang W, Cheng X, Ying M. Association between postoperative fluid balance and acute kidney injury in patients after cardiac surgery: a retrospective cohort study. J Crit Care. 2018;44:273-7. 
27. Goldstein SL, Currier H, Graf C, Cosio CC, Brewer ED, Sachdeva $\mathrm{R}$. Outcome in children receiving continuous venovenous hemofiltration. Pediatrics. 2001;107(6):1309-12.

28. Leary TS, Milner QJ, Niblett DJ. The accuracy of the estimation of body weight and height in the intensive care unit. Eur J Anaesthesiol. 2000;17(11):698-703.

29. Myles PS, Bellomo R, Corcoran T, Forbes A, Peyton P, Story D, Christophi C, Leslie K, McGuinness S, Parke R, Serpell J.
Restrictive versus liberal fluid therapy for major abdominal surgery. N Engl J Med. 2018;378(24):2263-74.

30. Brown RM, Semler MW. Fluid management in sepsis. J Intensive Care Med. 2018. https://doi.org/10.1177/0885066618784861.

Publisher's Note Springer Nature remains neutral with regard to jurisdictional claims in published maps and institutional affiliations. 